\title{
Updating Literacy Estimates in the Oklahoma City Metro
}

Olivia Campos, Alkin Huggins, Nelly Sime

Advisor: Tracy L. Morris

SCHOLAR, Department of Mathematics and Statistics, University of Central Oklahoma

\section{Introduction}

- Project SCHOLAR ${ }^{1}$ (Statistical Consulting Help for Organizational Leaders and Academic Researchers) is an undergraduate student statistical consulting service at UCO. SCHOLAR students work under the supervision of faculty mentors from the Department of Mathematics and Statistics on projects submitted by researchers on campus as well as off campus.

- This year's group was asked by the Oklahoma City (OKC) Metro Literacy Coalition ${ }^{2}$ to update estimates of literacy levels in the OKC metro area.

- Demographic variables were collected from the 2000 US Census $^{3}$ for all counties in $\mathrm{KY}, \mathrm{MD}, \mathrm{MA}, \mathrm{MO}, \mathrm{NY}$, and $\mathrm{OK}$, and were used to develop a model for predicting the 2003 State Assessment of Adult Literacy (SAAL) ${ }^{4}$ estimates.

- This model was applied to demographic data collected from the 2015 American Community Survey ${ }^{3}$ for every zip code in the OKC metro area, to obtain more recent estimates of below basic proficiency in literacy.

\begin{tabular}{|c|}
\hline Methods \\
\hline The statistical analysis was completed in three stages. \\
\hline 1. Univariate analysis: \\
\hline $\begin{array}{l}\text { Demographic variables from the } 2000 \text { US Census }{ }^{3} \text { for each county } \\
\text { in KY, MD, MA, MO, NY, and OK, were checked one at a time to } \\
\text { determine which variables are significantly related to the } 2003 \\
\text { SAAL }^{4} \text { estimates. }\end{array}$ \\
\hline $\begin{array}{l}\text { This was done by looking at the } p \text {-value, residual plot, and QQ-plot } \\
\text { for each demographic variable. }\end{array}$ \\
\hline $\begin{array}{l}\text { - Several variables, including the response variable, were log- } \\
\text { transformed to achieve linearity. }\end{array}$ \\
\hline $\begin{array}{l}\text { - Demographic variables with a p-value less than } 0.25 \text { were } \\
\text { considered for inclusion in the multiple regression model. }\end{array}$ \\
\hline - The univariate analysis was done using proc reg in SAS v. 9.4. \\
\hline 2. Multiple linear regression: \\
\hline $\begin{array}{l}\text { - Before performing the multiple regression, the remaining } \\
\text { demographic variables were checked for collinearity. }\end{array}$ \\
\hline $\begin{array}{l}\text { Multiple linear regression with stepwise selection was performed } \\
\text { on the group of variables remaining after the check for collinearity. } \\
\text { Summary statistics for the variables remaining after stepwise } \\
\text { selection are presented in Table } 1 .\end{array}$ \\
\hline $\begin{array}{l}\text { Interaction and quadratic terms were assessed for inclusion in the } \\
\text { model. Diagnostic plots and parameter estimates for the final } \\
\text { model are presented in Figure } 1 \text { and Table 3, respectively. }\end{array}$ \\
\hline - The final model was developed using proc reg in SAS v. 9.4. \\
\hline 3. Prediction: \\
\hline $\begin{array}{l}\text { The model was applied to demographic variables from the } 2015 \\
\text { American Community Survey for each zip code in the OKC metro } \\
\text { area. Summary statistics for these variables are shown in Table } 2 \text {. }\end{array}$ \\
\hline $\begin{array}{l}\text { Heat maps for the resulting estimates were constructed for OK } \\
\text { county and the OKC metro area. These are displayed in Figures } 2 \\
\text { and } 3 \text {, respectively }\end{array}$ \\
\hline $\begin{array}{l}\text { - The choroplethr package }{ }^{5} \text { in } \mathrm{R} \text { v. } 3.4 .1 \text { was used to draw the heat } \\
\text { maps. }\end{array}$ \\
\hline
\end{tabular}

in KY, MD, MA, MO, NY, and OK, were checked one at a time to

SAAL ${ }^{4}$ estimates.

for each demographic variable.

med to achieve linearity.

Before performing the multiple regression, the remaining

Multiple linear regression with stepwise selection was performed selection are presented in Table 1. model. Diagnostic plots and parameter estimates for the final

model are presented in Figure 1 and Table 3, respectively.

Prediction:

The model was applied to demographic variables from the 2015 Summunity Survey for each zip code in the OKC metro

Heat maps for the resulting estimates were constructed for $\mathrm{OK}$ and 3 , respectively

The choroplethr package ${ }^{5}$ in R v. 3.4.1 was used to draw the heat

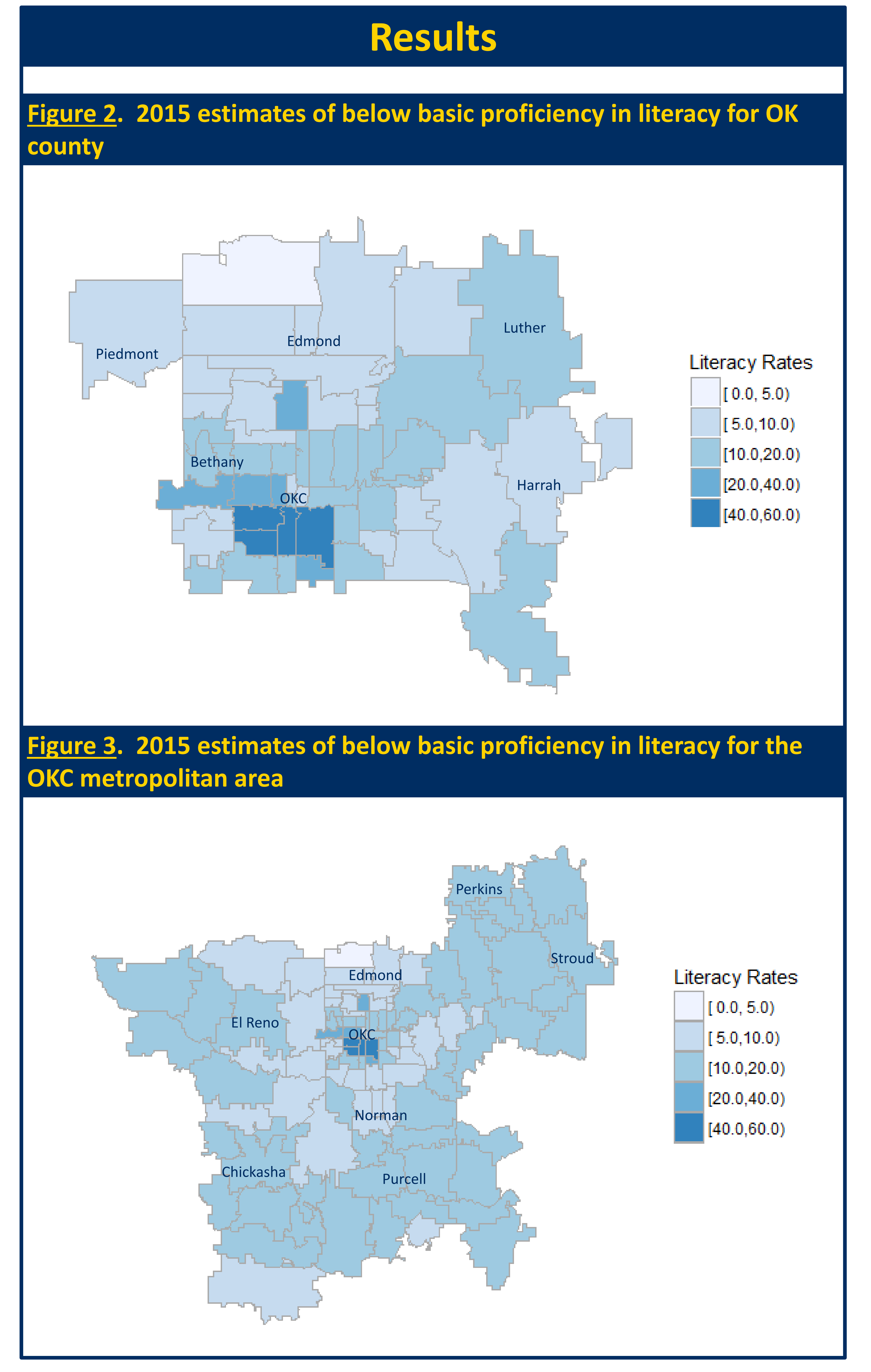

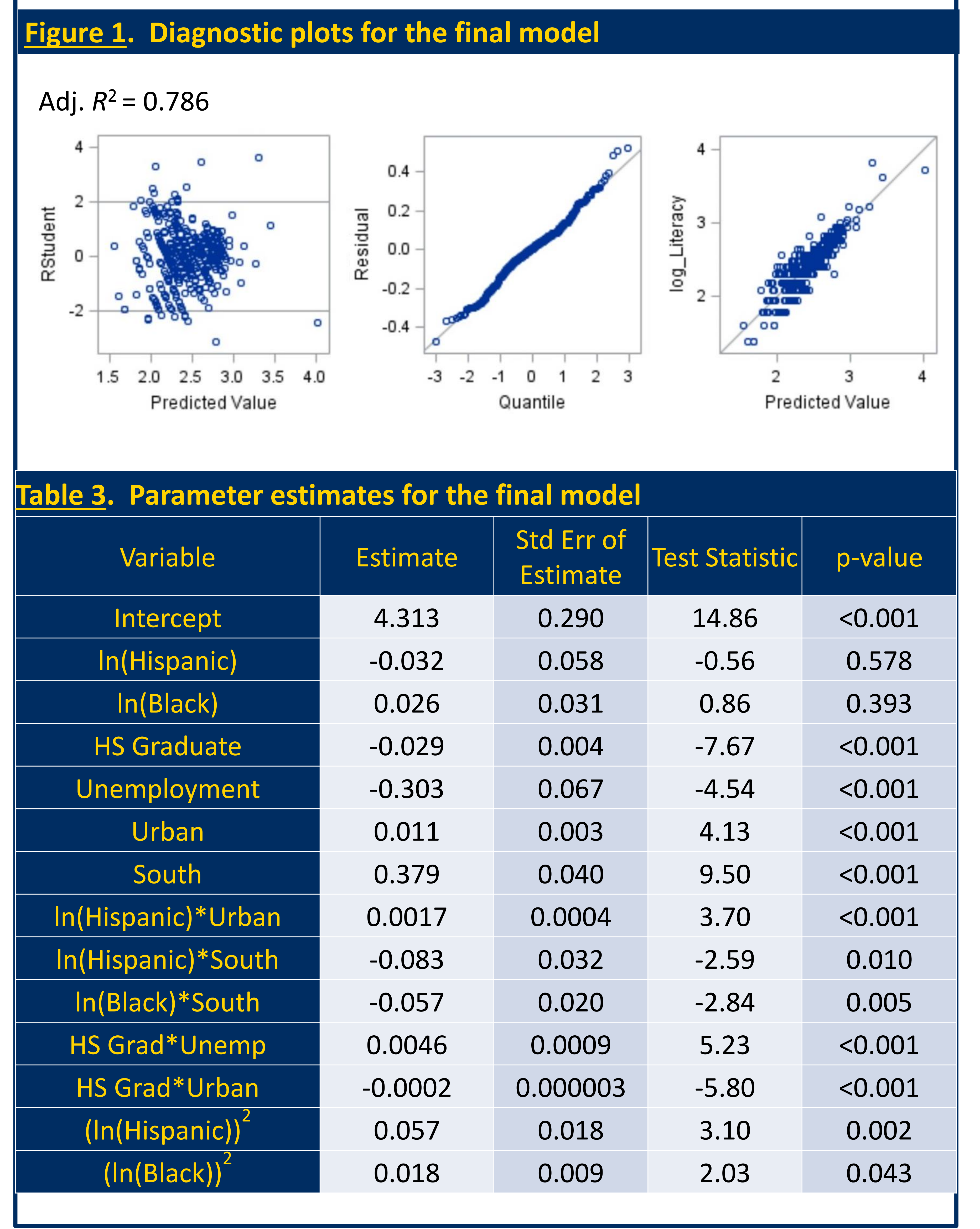

\section{Results}

\begin{tabular}{|c|c|c|c|c|}
\hline Variable & Mean & Std Dev & Minimum & Maximum \\
\hline Black & 4.8 & 7.5 & 0.0 & 64.3 \\
\hline Hispanic & 2.7 & 4.3 & 0.3 & 48.4 \\
\hline HS Graduate & 75.4 & 9.0 & 49.2 & 93.1 \\
\hline Unemployment & 3.4 & 1.1 & 0.8 & 8.2 \\
\hline Urban & 38.3 & 30.1 & 0.0 & 100.0 \\
\hline Literacy & 12.1 & 4.4 & 4.0 & 46.0 \\
\hline
\end{tabular}

Tab
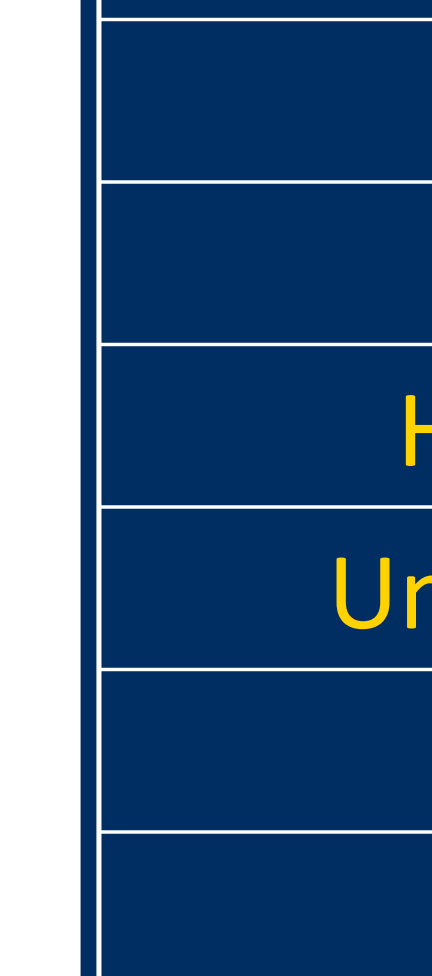

HS Graduate

nemployment

Urban

codes in the OKC metro area $(n=96)$

ta for

riable

lack

87

Mean

16.5

16.5
11.7

\section{7}

8.6

1.9

43.8

0.0

0.0

52.0

0.0

9.4 